\title{
Correlation between Motor Strategies of Balance Control and Causes of Fall in Post-Operative Elderly Individuals
}

\author{
Ishan Vivekanand Phatak¹, Sujit Ramesh Chavan², Sandeep Babasaheb Shinde ${ }^{3}$ \\ 1, 2,3 Department of Musculoskeletal Sciences, Krishna College of Physiotherapy, Krishna \\ Institute of Medical Sciences (Deemed to Be University), Karad, Maharashtra, India.
}

\section{ABSTRACT}

\section{BACKGROUND}

Falls are very much common in elderly. Fall in geriatric population is one of the common reasons for hospitalization, which may put financial burden on the patient and family. Fall in geriatric population many a times causes fracture and it may lead to serious complications which can threaten life. It may lead to disability and patient may become a handicap. In our study, we identified the correlation between motor strategies of balance control and causes of fall in post-operative elderly individuals.

\section{METHODS}

In this observational study, a total of 100 post-operative elderly individuals who had a fall and who underwent surgery for fracture correction were included. Both males and females in age group of 60 years and above were included. Outcome measures used were balance tests, manual muscle tests and goniometry.

\section{RESULTS}

$28 \%$ individuals had fall due to low level of motor control at ankle joint and $40 \%$ individuals at hip joint. In $16 \%$ of individuals reaching strategy was affected. Suspensory strategy was affected in $10 \%$ of individuals while stepping strategy was affected in $6 \%$ of elderly. Elderly had fall due to weak musculature at hip joint (35 $\%)$, knee joint (15\%), ankle joint (30\%) and spine (25\%) irrespective of the individual's gender.

\section{CONCLUSIONS}

Impairment in motor strategies of balance control such as, hip strategy, stepping strategy, reaching strategy, suspensory strategy, ankle strategy leads to fall in elderly. On the basis of assessment of manual muscle testing (MMT), range of motion and motor strategies of balance control, we concluded that impairment in motor strategies of balance, and reduced joint range of motion lead to falls.

\section{KEY WORDS}

Motor Strategies for Balance Control, Balance Tests, Manual Muscle Testing, Range of Motion
Corresponding Author: Dr. Sandeep Babasaheb Shinde, Associate Professor, Department of Musculoskeletal Sciences Krishna Institute of Medical Sciences (Deemed to Be University),

Karad, Maharashtra, India. E-mail: drsandeepshinde24@gmail.com

DOI: $10.14260 / \mathrm{jemds} / 2021 / 308$

How to Cite This Article:

Phatak IV, Chavan SR, Shinde SB. Correlation between motor strategies of balance control and causes of fall in postoperative elderly individuals. J Evolution Med Dent Sci 2021;10(20):1469-1473, DOI: 10.14260/jemds/2021/308

Submission 08-01-2021, Peer Review 18-03-2021, Acceptance 24-03-2021, Published 17-05-2021.

Copyright () 2021 Ishan Vivekanad Phatak et al. This is an open access article distributed under Creative Commons Attribution License [Attribution 4.0 International (CC BY 4.0)] 


\section{BACKGROUND}

Falls are one of the most common problems in geriatric individuals, approximately $30 \%$ of those over $65 \%$ will fall each year and rates of fall rises as age increases.1,2 Previously, the studies were done on motor strategies of balance control and also on causes of falls. But we have tested motor strategies with the help of balance test and causes of falls were identified, we also studied the correlation between motor strategies of balance control and cause of falls.

Fall may be due to impaired vision, giddiness, alcoholism, drug overdose, environmental factors such as slippery floor, poor lightening, stairs without handrails, high step height etc. Falls in geriatric individuals may cause fracture and complications of fracture, which may ultimately lead to the death of the individual. ${ }^{2}$ Falls may cause during daily activities too, some of them are while bathing, getting up from the bed or chair, climbing stairs or descending down on stairs, picking object from floor. In geriatric population, many individuals are not aware about the consequences of falls. In rural areas people are not aware about disabilities which may result due to falls. In many rural areas, people built their home by their own. So, the improper architectural factors may also contribute to the falls.

As age advances, degenerative changes start taking place in musculoskeletal system, nervous systems and cardiorespiratory system. Also, decline in special senses like visual activities, hearing, taste, smell, touch and vestibular system can also be cause of falls. ${ }^{3}$ These changes alter normal gait pattern and also affects balance which may lead to falls. ${ }^{4}$ Also falls can be due to either balance deficit or gait deficit. ${ }^{5}$ Elderly people may experience decreased muscle power, reduced joint range. There are certain things which may lead to falls, like environmental factors and individual's personal factors. ${ }^{5,6}$

The most common fall related injuries are osteoporotic fracture. ${ }^{7}$ Falls may cause fracture of neck of femur, Colle's fracture, inter-trochanteric fracture of femur, supracondylar fracture, humeral shaft fracture etc. ${ }^{8}$ Due to fall, patient experiences mental stress along with burden on other family members. ${ }^{9}$ Cost of hospitalization and treatment of fracture and other soft tissue injuries affects widely on financial status of patients. ${ }^{10}$ Many patients are facing problems while doing day to day activities. ${ }^{11}$ The overall functional capacity of an individual is reduced and the ability to perform the basic activities of daily life is reduced. ${ }^{12}$

Due to lack of awareness and medical services in rural areas, many people suffer from complication of falls. ${ }^{13}$ Earlier studies were done on motor strategies of balance control and causes of falls in elderly but the correlation between motor strategies of balance control and causes of falls is not studied yet, so we have identified correlation between these two and is studied. Thus, understanding the correlation will help to intervene effectively to prevent falls.

Prevention and management of falls has become important part of healthcare profession as it may cause disability and loss of independence. ${ }^{14}$

Physiotherapy plays an important role in elderly individuals in an order to improve the quality of life and functional activities. They reduce the chances of falls in elderly by improving motor strategies of balance control. Physiotherapist can work on avoidable causes of falls such as range of motion of joints, gait pattern, balance and co - ordination training, improved muscle strength in geriatric population. Physiotherapist works on musculoskeletal system by increasing muscle strength, muscle power and endurance. This training reduces overall risks of fall in elderly individuals.

In our study, we identified the correlation between motor strategies of balance control and causes of fall in postoperative elderly individuals.

\section{METHODS}

This was an observational study with total of 100 participants. The samples were selected by the convenient sampling technique. The participants were elderly individuals who had a fall and underwent surgery for fracture correction. Both males and females in age group of 60 years and above were selected for the study.

Participants were selected from Krishna Hospital, Karad. The study duration was 6 months. Outcome measures included were balance tests, manual muscle tests, and goniometry. Ethical clearance was obtained from the Institutional Ethical Committee of Krishna institute of medical science deemed to be university, Karad. The data was collected from 21st November 2019 to 30th December 2019. Data was collected and procedure was supervised by faculty in charge.

\section{Procedure}

The inclusion criterion and exclusion criterion for the study was decided first. Subjects were selected and were requested to participate in the study. The nature of the study was explained to the subjects. The consent was taken from the subjects. The criterion for selection was participant should be above 60 years of age who had fall and should be treated for the fracture surgically. Architectural factors responsible for falls will be included. Falls caused due to surface level, during bathing, related to chair activities will be included.

Falls caused due to musculoskeletal problems such as arthritis, muscle weakness, pain and stiffness were included. The patient was assessed after 3 months of surgical correction for treating fracture. Assessment of range of motion of hip, knee, ankle and spine was taken with the use of goniometer.

Manual muscle testing of hip, knee, ankle, spine was also taken. After that, motor strategies such as, hip strategy, reaching strategy, suspensory strategy, ankle strategy and stepping strategies were assessed with the balance tests. Following are the balance tests which are used for the assessment such as Romberg test, patient is asked to stand in normal comfortable position and observations are noted. Then the subject is asked to stand on single leg, patients were asked to stand with feet together.

After that, patients were requested to climb the stair without handrail. At last for assessing stepping strategy, subjects were asked to step forward and backward. Thus, the study was concluded by statistical analysis of the outcome measures.

\section{Subject Selection}

The sample size was calculated with the formula $n=4 p q / L .^{2}$ The participants selected were elderly individuals who had a 
history of fall and who had undergone surgery for fracture correction.

Both males and females in age group of 60 years and above were selected for the study. On the basis of inclusion and exclusion criteria patients who were operated in Krishna hospital, Karad were selected for the study. Patients who fall due to architectural factors and musculoskeletal problems were included.

Written informed consent was taken from the participants those willing to participate. The participants were allocated by simple random sampling method. The detailed outcome assessment was done by using musculoskeletal assessment protocol.

\section{Outcome Measures}

1. Romberg test

2. Standing in normal comfortable position

3. Single leg stance

4. Standing with feet together

5. Stair climbing without handrails

6. Forward steps and backward steps

\section{Statistical Analysis}

The outcome measures were assessed at the baseline. The collected data in this study was statistically analysed using descriptive statistics as pie chart, bar diagram and percentages. Final results were calculated in the form of percentages (\%).

\section{RESULTS}

Graph 1. (A) Shows the percentage of participants affected among 100 subjects with different motor strategies of balance control. In that we found that, hip strategy was affected in 40 $\%$ of individuals.

\begin{tabular}{|c|c|c|c|}
\hline Sl. No & \multicolumn{2}{|c|}{ Demographic Variables } & $\%$ \\
\hline \multirow{3}{*}{1} & \multirow{3}{*}{ Age } & $60-65$ years & $42 \%$ \\
\hline & & $66-70$ years & $35 \%$ \\
\hline & & 70 above & $23 \%$ \\
\hline \multirow{2}{*}{2} & \multirow{2}{*}{ Gender } & Males & $53 \%$ \\
\hline & & Females & $47 \%$ \\
\hline 3 & \multicolumn{2}{|c|}{ Obesity $\left(\mathrm{BMI}=>24.9 \mathrm{~kg} / \mathrm{m}^{2}\right)$} & $37 \%$ \\
\hline 4 & \multicolumn{2}{|c|}{ Elderly who attended fall prevention programme } & $0 \%$ \\
\hline \multirow[b]{2}{*}{5} & \multirow{2}{*}{ Living area } & Rural area & $56 \%$ \\
\hline & & Urban area & $44 \%$ \\
\hline 6 & \multicolumn{2}{|c|}{ Elderly who are having diabetes mellitus } & $29 \%$ \\
\hline 7 & \multicolumn{2}{|c|}{ Elderly who are having hypertension } & $34 \%$ \\
\hline 8 & \multicolumn{2}{|c|}{ Elderly who are taking medications for thyroidism } & $4 \%$ \\
\hline 9 & \multicolumn{2}{|c|}{ Elderly who are alcohol addicted } & $36 \%$ \\
\hline \multicolumn{4}{|c|}{ Table 1. Demographic Variables } \\
\hline
\end{tabular}

Reaching strategy was affected in $16 \%$ of individuals. Ankle strategy was impaired in $28 \%$ of patients. Suspensory strategy was affected in $10 \%$ of patients. Stepping strategy was affected in $6 \%$ of individuals.

Graph 1. (B) shows the percentage of participants affected among 100 subjects with range of motion. In that we found that, range of motion at hip joint was affected in $55 \%$ of individuals. Knee joint range of motion was affected in $10 \%$ of individuals. Range of motion at ankle joint was affected in 30 $\%$ of patients. Range of motion at spine was affected in $5 \%$ of patients.
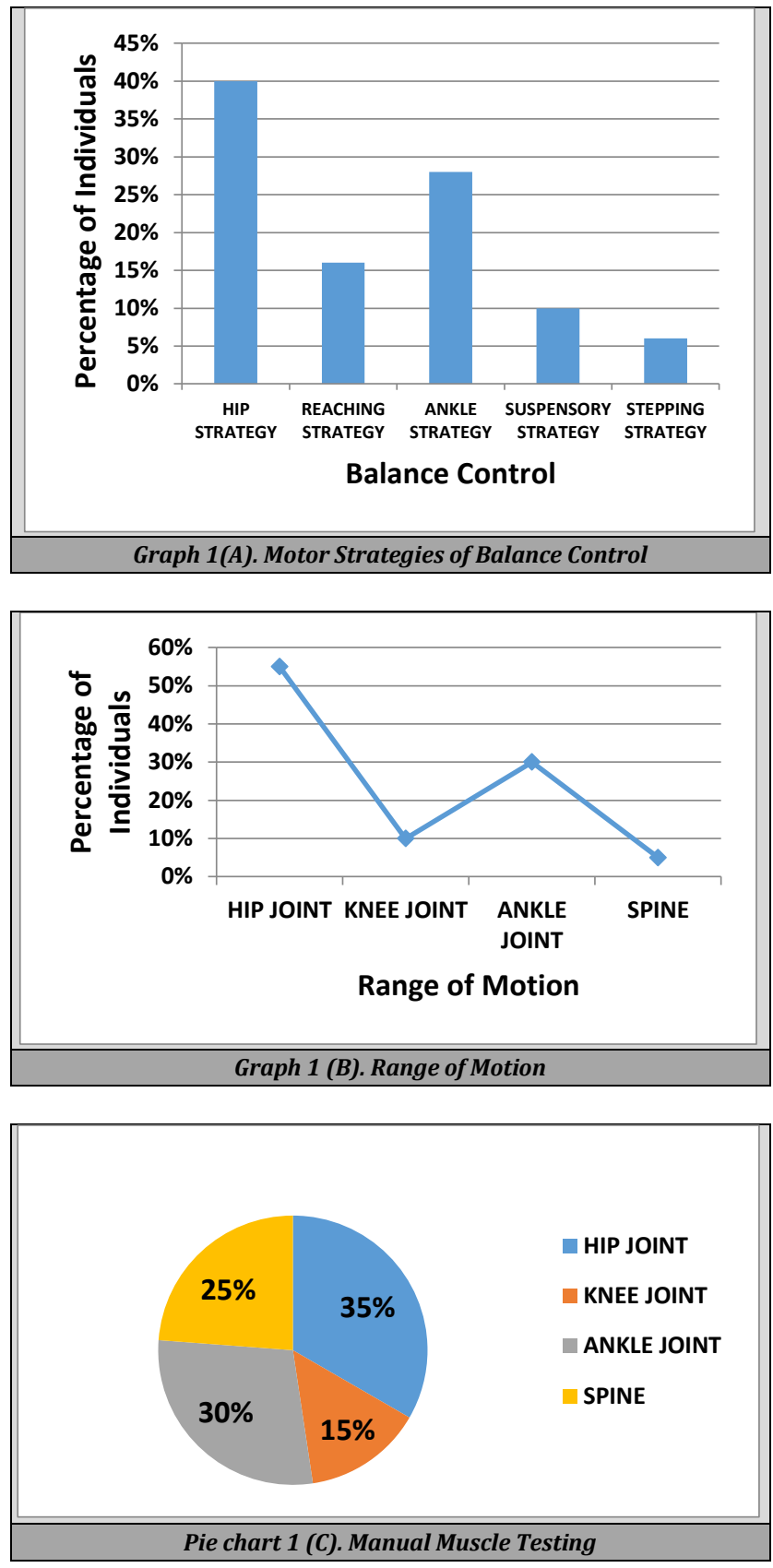

\section{Pie Chart}

This chart shows the percentage of participants affected among 100 subjects with muscle power. In that we found that, $35 \%$ of subjects were having weak hip musculature. Knee joint musculature was found weak in $15 \%$ individuals. $30 \%$ of elderly were having ankle joint weakness. $25 \%$ of elderly individuals were having spine musculature weakness.

\section{DISCUSSION}

Falls affects badly on an individual personal and social life. Fall is one of the main causes of getting admitted in hospital. As we all know fall is one of the common reasons for making person disabled, and disability may result into psychological stress, financial burden on patient and family.

Motor strategies of balance control plays an important role for maintaining body's equilibrium and balance during sitting, walking, or doing daily living activities etc. Impairment of 
motor strategies affects body's equilibrium. So, fall may occur in an individual whose motor strategies are impaired.

As age increases, there are some changes occurring in all the system like musculoskeletal system, cardiopulmonary system, vestibular system which may alter motor strategies in elderly. ${ }^{3}$ Osteoporosis is one of the common reasons for causing fractures like hip, knee, ankle etc. ${ }^{7}$ Some fractures may result into severe complications such as hypovolemic shock, deep vein thrombosis, malunion etc. ${ }^{8}$

In geriatric population, falls are the commonest reason for disability. ${ }^{14}$ Motor strategies such as muscle power and range of motion are important to maintain normal gait.15,16 Previously, there are studies done on motor strategies of balance control and causes of falls, but the correlation between motor strategies balance control and causes of fall was not yet done so we selected this topic to find out the correlation between them. So, the study was started by taking postoperative elderly individuals who are above 60 years old. Demographic variables such as name, age, gender, were noted. Assessment of range of motion, manual muscle testing was done. Motor strategies of balance control were assessed with the help of following balance tests, Romberg test, standing in normal comfortable position, single leg stance, standing with feet together, stair climbing without handrails, forward steps and backward steps. ${ }^{17}$

The study concluded that impairment of motor strategies of balance control leads to fall in elderly. The other factors included are altered, reduced range of motion, low grade of MMT, environmental factors due to poor infrastructure are also risk factors for fall. In future, this study can be done by taking a greater number of sample size. This study is helpful mainly for geriatric population. By the help of this we can assess elderly individuals for the risk of fall. And we can predict the risk of fall in elderly.

We can plan physiotherapy treatment in order to improve the motor strategies of balance control with the help of this assessment. By improving the motor strategies of balance control, we can avoid the falls in elderly population. Also, through improvement in motor strategies of balance control, gait, balance, posture of an individual is maintained normal. Implementation of closed kinetic chain exercises, ${ }^{18}$ increased muscle strength and normal range of motion will also help to avoid falls in elderly. And by avoiding falls, economic burden of surgical procedures, complications such as pressure ulcers have been associated with an extended length of hospitalization, sepsis and mortality. ${ }^{19}$ complications of immobilization and bed rest can be avoided. Multicomponent ${ }^{20}$ therapeutic exercise program and ${ }^{21}$ conditioning program ${ }^{22}$ will further positively improve functional status and quality of life in elderly.

\section{CONCLUSIONS}

Based on assessment of manual muscle testing, range of motion, and motor strategies of balance control, we concluded that impairment in motor strategies of balance, and reduced joint range of motion, lead to falls. Implementation of exercise program is a must to improve motor strategies of balance control which is important for fall prevention strategy in elderly.
Data sharing statement provided by the authors is available with the full text of this article at jemds.com.

Financial or other competing interests: All Authors received grants from Krishna Institute of Medical Sciences Deemed to Be University Karad.

Disclosure forms provided by the authors are available with the full text of this article at jemds.com.

\section{REFERENCES}

[1] Biderman A, Cwikel J, Fried AV, et al. Depression and falls among community dwelling elderly people: a search for common risk factors. J Epidemiol Community Health 2002;56(8):631-6.

[2] Krishnaswamy B, Usha G. Falls in older people. Chennai: Madras Medical College 2003.

[3] Paraschiv C, Esanu I, Ghiuru R, et al. General principles of geriatric rehabilitation. Romanian Journal of Oral Rehabilitation 2015;7(1):76-80.

[4] Woollacott MH, Tang PF. Balance control during walking in the older adult: research and its implications. Phys Ther 1997;77(6):646-60.

[5] Fong KNK, Siu AMH, Yeung KA, et al. Falls among the community-living elderly people in hong kong: a retrospective study. Hong Kong Journal of Occupational Therapy 2011;21(1):33-40.

[6] Menz HB, Morris ME, Lord SR. Foot and ankle risk factors for falls in older people: a prospective study. J Gerontol A Biol Sci Med Sci 2006;61(8):866-70.

[7] Hefny AF, Abbas AK, Abu-Zidan FM. Geriatric fall-related injuries. Afr Health Sci 2016;16(2):554-9.

[8] Maheshwari J, Mhaskar VA. Essential orthopaedics: (including clinical methods). Jaypee Brothers Medical Publishers 2019.

[9] Potasznik H, Nelson G. Stress and social support: the burden experienced by the family of a mentally ill person. Am J Community Psychol 1984;12(5):589-607.

[10] Siracuse JJ, Odell DD, Gondek SP, et al. Health care and socioeconomic impact of falls in the elderly. Am J Surg 2012;203(3):335-8.

[11] Fuller GF. Falls in the elderly. Am Fam Physician 2000;61(7):2159-68.

[12] Evans WJ, Campbell WW. Sarcopenia and age-related changes in body composition and functional capacity. J Nutr 1993;123(2 Suppl):465-8.

[13] Kamble SV, Ghodke YD, Dhumale GB, et al. Health status of elderly persons in rural area of India. Indian Medical Gazette 2012:295-9.

[14] Himes CL, Reynolds SL. Effect of obesity on falls, injury and disability. J Am Geriatr Soc 2012;60(1):124-9.

[15] O'Sullivan SB, Schmitz TJ, Fulk G. Physical rehabilitation. $7^{\text {th }}$ edn. Phildelphia: FA Davis 2019.

[16] Alghwiri AA, Whitney SL. Balance and falls. In: Guccione AA, Wong RA, Avers D, eds. $3^{\text {rd }}$ edn. Geriatric Physical Therapy. St. Louis: Elsevier Mosby 2012: p. 331.

[17] Marks R, Allegrante JP, Mackenzie CR, et al. Hip fractures among the elderly: causes, consequences and control. Ageing Res Rev 2003;2(1):57-93.

[18] Jagdishbhai SR, Shinde SB. Effect of closed kinetic chain exercises in subjects with proximal femur fracture operated with dynamic hip screw and plate fixation. 
Indian Journal of Physiotherapy and Occupational Therapy 2017;11(2):98.

[19] Shinde SB, Varadharajulu G. Impact of pressure ulcers on therapeutic outcomes in inpatient physiotherapy services. J Evolution Med Dent Sci 2020;9(31):2187-90.

[20] Kulkarni P, Shinde SB. Effect of multicomponent exercise program on selected gait and balance parameters in young obese females. J Evolution Med Dent Sci 2020;9(23):1739-42.
[21] Shinde SB, Varadharajulu G. Effect of therapeutic exercise programme in adults with early rheumatoid arthritis. Indian J Physiother Occup Ther 2017;11:76-80.

[22] Kolhatkar AS, Shinde SB. Effectiveness of a conditioning program on amateur female marathon runners. Journal of Evolution of Medical and Dental Sciences 2020;9(29):2040-4. 